\title{
Managers' perception of potential impact of knowledge management in the workplace: Case study
}

\author{
Professor Khalid Alrawi and Walid Alrawi \\ American University in the Emirates, Alkhawarizmi International College, \\ College of Business Administration, United Arab Emirates
}

\begin{abstract}
This paper is an exploratory research that reviews how organization managers perceive knowledge management (KM), and practice across all levels of their firms. The paper posits that $\mathrm{KM}$ consists of enablers such as top management commitment and knowledge structure that are critical to the success of a knowledge-based organization. The study was stimulated firstly, the recognition of shifting businesses from production-based to a knowledge-based economy, secondly the emergence of the needs for knowledge managers, as well as learning organization. The paper also addresses all top management leaders (levels of decision making) in the study. The study is conducted in Abu Dhabi, Al-ain, United Arab Emirates (UAE), and the study represents all firms according to "The Chamber of Commerce Directory". Based on the sample of 112 firms, finding reveal that managers' perception in these firms was a key barrier for achieving success and positive performance. Findings reveal that although business growth and a large market size were seen to motivate firms locally, perceiveness of the potential KM effectiveness to increase efficiency of the organization was lagging behind, and therefore understanding $\mathrm{KM}$ was a barrier.
\end{abstract}

Keywords: Knowledge Management, knowledge Creation, Managers' Perceptions, Managers Commitments, Decision Making.

\section{INTRODUCTION}

Knowledge management is a structured process that enables knowledge to be created, stored, distributed, and applied to decision making (Alavi and Leidner, 2001). The experience from industries has identified the necessary factors that are required to ensure success of KM approach, and also to increase the effectiveness of an organization. Knowledge management involves human resources, organization policy and culture, information technology, tools and methods that support and enable it (Nissen, 2002). In this respect KM typically follows different steps, create, capture and share the knowledge. KM aims to discover research and study knowledge. Therefore, $\mathrm{KM}$ system is a tool aimed to support knowledge sharing, the creation, capture organization and dissemination of data, information and knowledge within and across the departments or communities of practice with similar interests and needs (Chang, et.al, 2005).

One promising tool for knowledge development and management is the notion of learning object repositories, a repository for information and knowledge. Like a library, the repositories' purposes are to maintain a collection to meet the growing needs and demands for informational, research or recreational needs of its users (Kanuka, and Garrison, 2007). To make a KM work efficiently and effectively it must be a local and personalized. The question is what infrastructure is required to support the organizations' management that also could be grown to support broader institutional needs?

In an organization $\mathrm{KM}$ duties comprises of organizing, transferring, locating and ensuring the usage of information and expertise within the organization. The enablers support for such a process is the culture of the organization, leadership perception, the technology used and measurement of achievement. Within such understanding management use the processing capabilities to take effective action to achieve the firms' goals (Oliver and Kandadi, 2006).

This paper investigates managers' perception about KM effects within their organizations' working environment, their beliefs is regarded as a major factor that could encourage the practice of KM. Such belief influences knowledge creation through opportunities, motivation, and capability for knowledge combination in their organization. Therefore this paper implies that further theoretical 
research be conducted on the relationship between the various objectives for KM benefits to enhance this exploratory research. Now there is recognition that business is a knowledge-rich activity and that $\mathrm{KM}$ in business is a priority. Firms have recently recognized the potential for $\mathrm{KM}$ to improve the quality of achievement. An understanding of $\mathrm{KM}$ is now important for any business employer especially for those interested in work based learning for firms and its management in the UAE.

The researcher believes that the findings will help to shed valuable insights for business support organizations concerning managers' perceptions towards $\mathrm{KM}$, and the necessities to change such perceptions.

The conceptual framework for this study is based on direct interview where a questionnaires addressed those managers, and the observation that information flows are enhanced or inhibited not only by accepted procedures and norms but also may be enabled or constrained by systems or information technology as far as KM may involve both technical and human entities behave on each other dependently.

Organizational Knowledge and End Results: The three entities mentioned in the introduction section (i.e., opportunities, motivation, and capabilities), have a recursive relationship. Changes in one can enable or inhibit changes in the other (King and Marks, 2008). In fact these elements represent a conceptual framework regarding managers' perception, and use of information technology used in their organizations as a culture in the workplace, and one may think about the creation, access, distribution and the application of knowledge within the organization. Figure (1) illustrates the relationships among the three variables mentioned above.

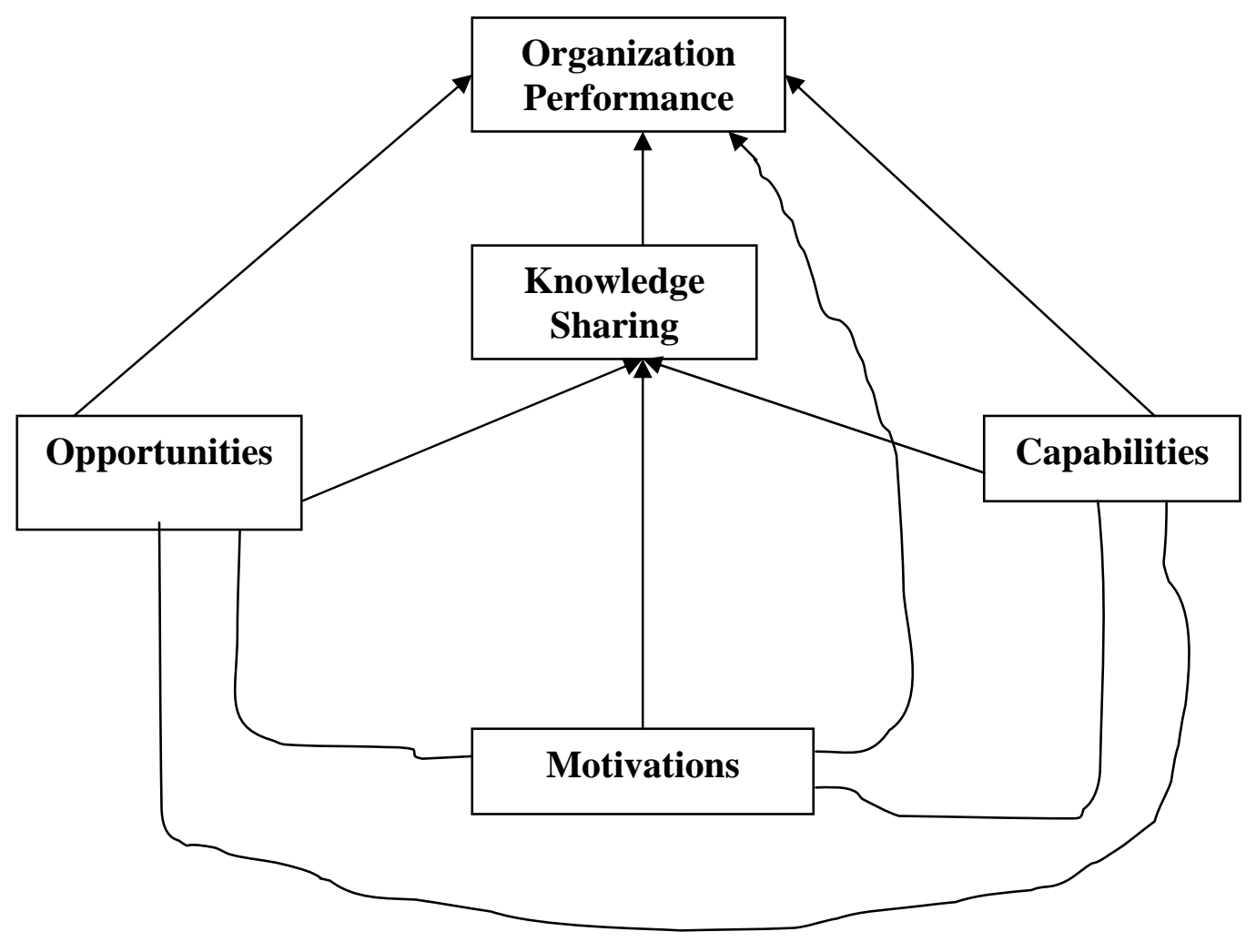

Fig 1: Effects of Knowledge Sharing Influence

Figure (1) permits and explain, the interchange relationships between variables affecting knowledge sharing and the organization performance. These three variables should be perceived by managers as a way in which knowledge may affect organizational performance. If this is the case in the organization, 
such situation interprets by the existence of the positive relationship between knowledge sharing and firms' performance (Van, 2005). In an industrial firm, positive relationship means the existence of collaboration and knowledge sharing between departments and employees in terms of manufacturing, quality and research and development, and this will lead to the increasing in productivity and performance. Then manager's contribution is vital. Managers should be aware that sharing knowledge in a meaningful manner requires a well balanced merge of technology with a firms' culture that create a climate or an environment enhancing collaboration. Advanced knowledge gives an organization a competitive advantage. It is a specific knowledge that gives specific organization a competitive edge (Bechky, 2003). With the core knowledge, the management differentiates its organization from its competitors in that particular industry or sector. The role of manager to play in such situation could be achieved through the connection between firm's competitive situation and a KM strategy to help their firm's maintaining or reestablish its competitive advantage. As firms differ from each other in terms of product, industry, or sector, therefore, management will find its own unique link between knowledge and strategy (Kim and Street, 2004). Then some organization will concentrate on their relationship with their customers by increasing customer satisfaction and their needs and wants. However, other organization may develop new ideas, invent innovation and get them to market quickly, or may focus on themselves and their internal logistical capacity and capabilities. Such discipline is reflected in Figure (2).

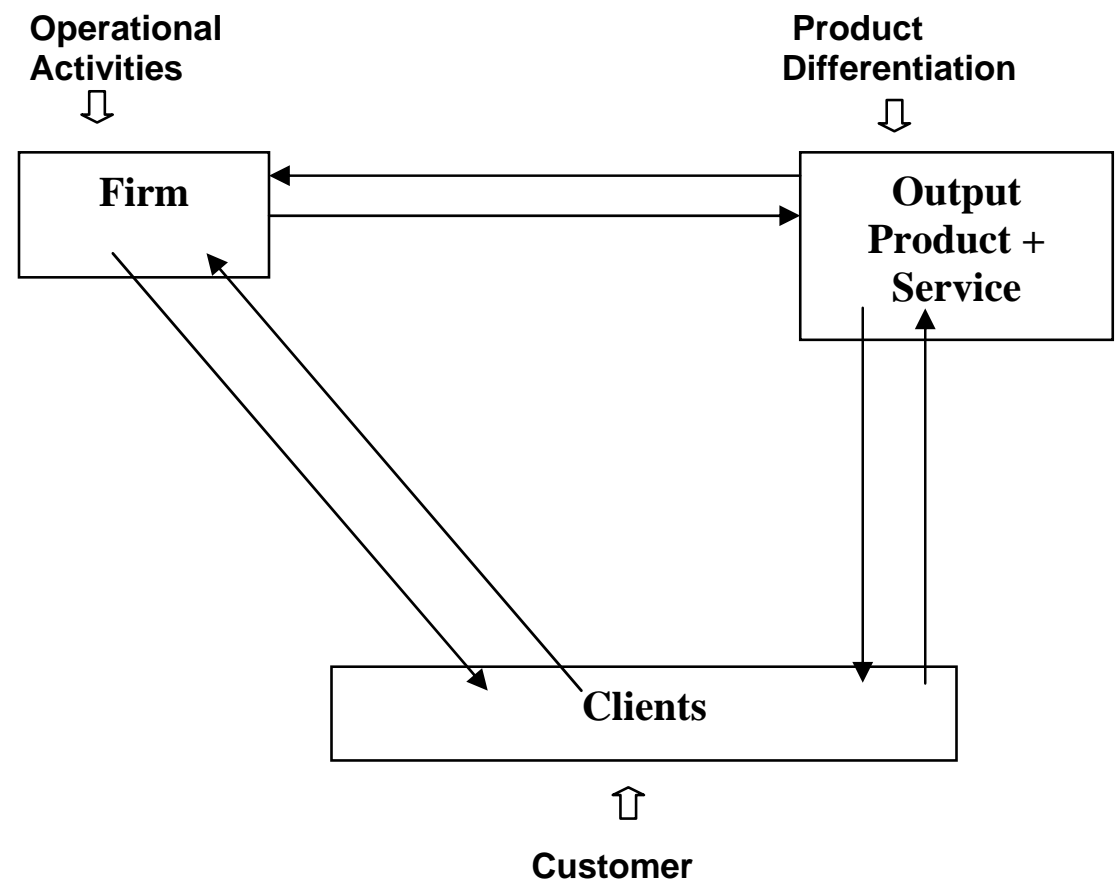

Fig 2: Organization Focus for Value

Satisfaction Trust between these pillars is an important element which affects knowledge in the organization's working environment. The result is improvement in transferring of information, the communication networking.

Managers therefore, should recognize that understanding knowledge requires some grasp of its relationship to information (King, 2006). The recognition of interacting through distinguishing between information data arranged to meaningful pattern and knowledge which has been regarded as an element should be true, and reliable. Such practicing of knowledge may enabling managers of setting a method or approach or a strategy, and 
enabling their firms embodied principles and moral (Kankanhalli et.al.,2003). Management at the end is regarded as an enabler's support to the KM process, through the quality of leadership, recognition of cultural effect, the suitable technology used and measurement of achievement or performance. For effective ongoing knowledge creation executives should understand that $\mathrm{KM}$ is a way of organizing information, transferring information, experience, and personal skills. (Keulartz, and Schermer, 2004).

The implications for Work Based Learning: Knowledge management involves many organizational activities that are aimed at improving knowledge-related practices, organizational behavior and performance.

Knowledge management is based on the premise that just as human beings are unable to draw on the full potential of their brains; organizations are generally not able to fully utilize the knowledge possessed by individual employees as well as that which exists collectively within the organization (Lamb and Kling, 2003). Through KM, organizational knowledge may be managed to create new knowledge. The knew knowledge is created knowledge sharing between employees within the environment of the organization. Therefore innovation and knowledge are linked to knowledge sharing. Through KM, organizations seek to acquire or create potentially useful knowledge and to make it available to those who can use it at a time and place that is appropriate for them to achieve maximum usage and maximal impact on organizational performance (King, 2007). Thus, the true value is created by fostering innovation in the organization. In this respect the organization must consider knowledge as strategic assets, and these organizations should capitalize on existing organizational knowledge to improve and build up an intellectual assets base as an attempt to gain a competitive advantage.

Based on general acceptance between businessmen, the researcher believes that the success of $\mathrm{KM}$ strategies is to a large extent determined by the support from top and middle-level management (Rus and Lindvall, (2002). Leadership is essential to stimulate staff motivation to access the various sources of knowledge and to encourage employees to share their tacit knowledge (Kuo and Chu, 2004). Managers use the information technology to build the infrastructure that is required to support the core activities of storing and distributing knowledge. With the spread of technology and efficient communication network management has different choices and alternatives to enhance information technology support to KM. The aim of this information technology is sharing, capturing, leveraging for further learning and innovation among employees. Figure (3), reflecting these thoughts.

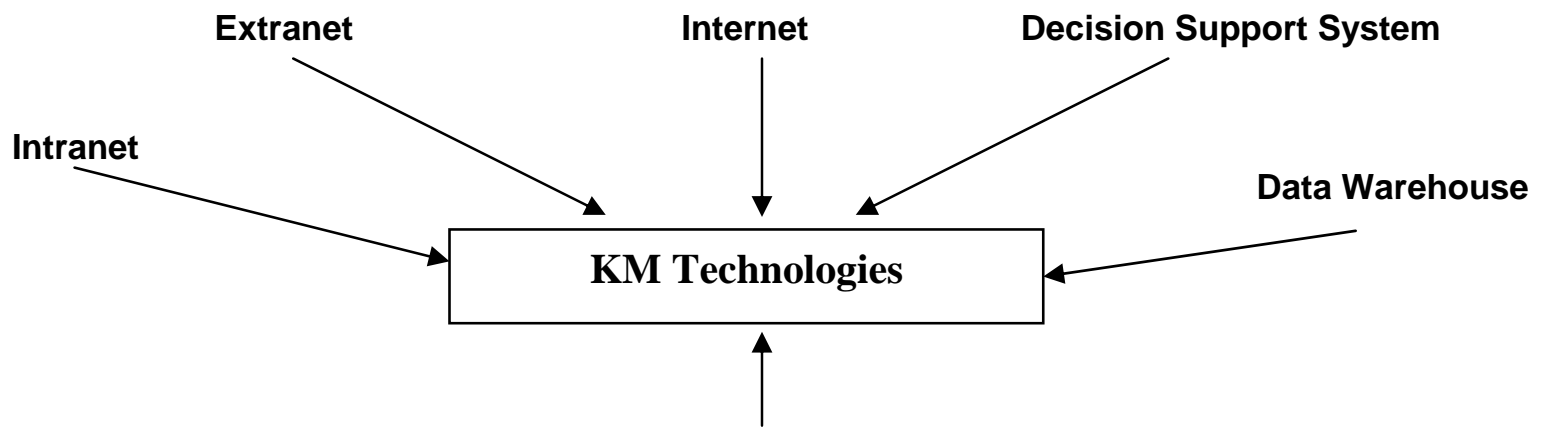

Project Management

Fig 3: Variables Affecting Knowledge Management

The practices of these variables depend on mangers perceptions and the stage of organizational investment in ad hoc KM software that facilitates organizational knowledge. Training programme may be required to enhance development of standards and best practices of knowledge and management efficiency. Therefore based on KM progress mentioned above, it can be fairly said that $\mathrm{KM}$ is not a technology; in contrast, technology is fundamental to KM progress (Ali and Ahmad, 2006). The application of such thought depends mainly on the culture of the organization in absorbing new ideas and experiences both from within and outside the organization to develop a process to achieve success (Thiessen and 
Looker, 2007). Therefore, some organizations may concentrate on their leadership with customer, other organizations may focus on their products and services, and other group may focus on their organizational processes and the internal structure. Figure (4); reflects such focuses by organizations for a better use of knowledge.

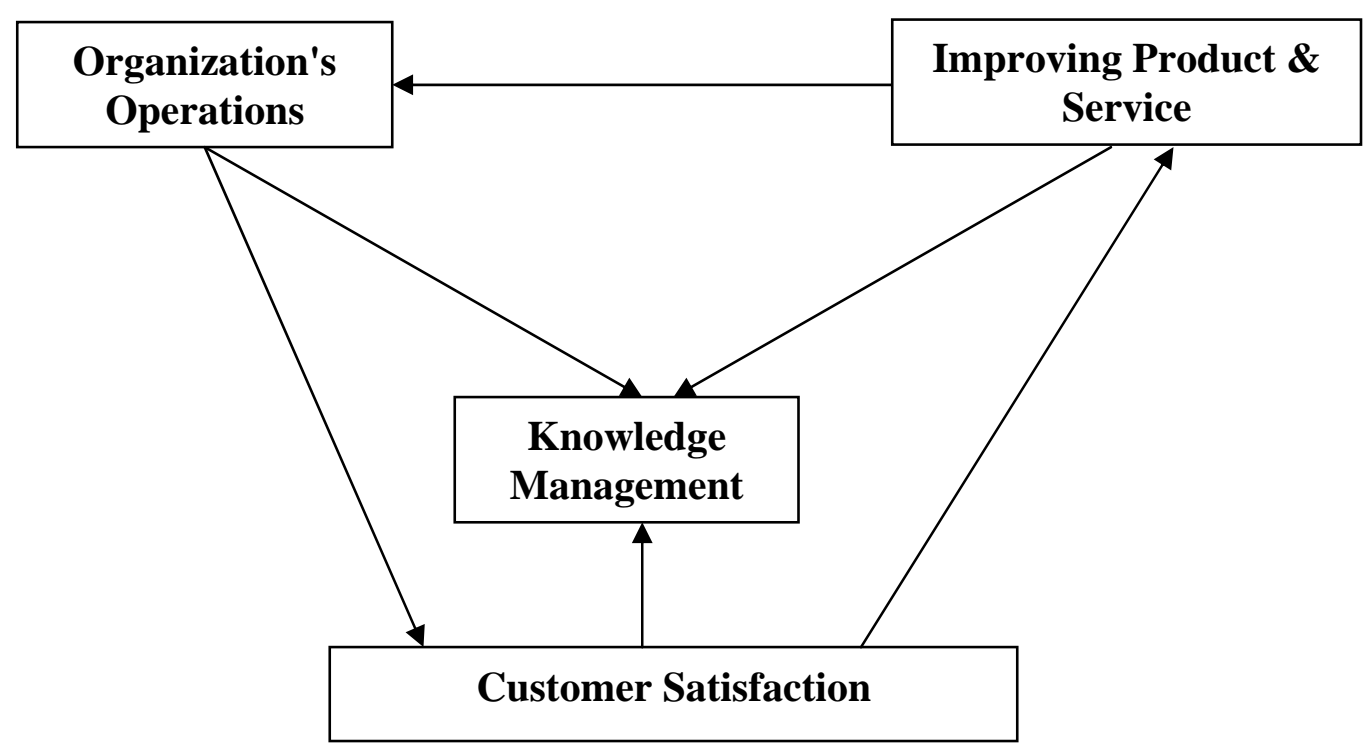

Fig 4: Organizational Focuses on Knowledge Values

In general in order to build a KM strategy management may use the SWOT analysis approach (Strength, Weaknesses, Opportunities, and Threats) to identify the strategic gap in their organization's knowledge. Such analysis enables the organization to identify where it has the knowledge which it can exploit and, where it can exploit in the above three possibilities. Thus, organizational knowledge creation processes are influenced by social phenomenon. These are the three elements of knowledge capital which represent and comprise the organization's stock of intangible assets (Saint-Onge, 1998).

According to Nahapiet and Ghoshal (1998), sharing norms and values enable a group of people to exchange their knowledge. Such norms and values include a response to diversity, openness to criticism, and a tolerance of failure which facilitate group think, that shows a high level of knowledge creation. Therefore, KM is a social process, and more than data management. In the business world today, an organization's competitive edge almost wholly depends on how well it can manage and deploy its corporate assets, either tangible or intangible
(Wathen and Burkell, 2002). The environment forces such as competitive advantage by managing knowledge well, or the requirement of the organization to distribute its knowledge among its organizational hierarchy may compel-the organization to initiate a knowledge management programme in a way that creates an environment supporting collaboration. Therefore managers' tasks are to ensure sharing information in a collaborative form and aware of the information technology resources are available (Papoutsakis, 2006).

The level of corporation and trust between management and employees in turn provides the basis for establishing employees' loyalty to their firms. The convergence of perspectives required to have an effective partnership will be best achieved through on-going knowledge sharing and strategic discussion between the organization and employees (Menon and Pfeffer, 2003).

Research Approach: The research's design adopted for this study is exploratory in nature to obtain preliminary insights into the managers' behavior 
toward $\mathrm{KM}$ among industrial firms in UAE. A questionnaire survey was adopted as the principle method for data collection, which suited the financial and time constraints of the research project. The findings provide the opportunity for all firms to participate. Abu Dhabi Directory of durable products and services are used as the sampling frame for the study and in total (112) manufacturing firms was listed. Total confidentiality was guaranteed for all respondents and this was clearly highlighted in the covering letter. In total, the questionnaires were eventually used for data analysis represented a (76) percent response rate which was perceived to be adequate for the exploratory nature of research investigation.

Findings and Results: In current and emerging business contexts our understanding of what creates competitive value for organizations has changed radically. In many cases the long-term prosperity of an organization now depends to a large extent on its $\mathrm{KM}$ capabilities. KM is the ability to develop, maintain, leverage and renew this type of intangible assets (Saint-Onge, 1998). Therefore, managers are able to manage the knowledge for the benefit of their firms. In the knowledge economy, the quality of relationship between $\mathrm{KM}$ and performance will determine the extent to which value is added to the organization.

The researcher addresses the following question to the managers in the sample: What is KM?

The majority of the respondents (85\%) defined KM as the accumulation of personal experience within his work. To those managers then KM is what they learn from their work, in fact they mentioned to what is known " Tacit Knowledge". This knowledge then may store in the brain of a worker, but it may be possible to convert certain aspects of it into " Explicit Knowledge"-what is stored in a variety of formats, such as on the shelves of libraries and in electronic data. The researcher believes that as far as those respondents have traditional understanding of what knowledge is, he is in doubt that those managers have the capabilities and familiarity to possible converse their aspects into explicit knowledge. New explicit knowledge can be created from research and from the conversion of tacit into explicit knowledge. However, new tacit knowledge is developed by the daily experiences of individuals and by the internalization of explicit knowledge (King and Lekse, 2006).
The researcher's conclusion is based on the fact that managers in the sample have no perception of the collective knowledge; a social constructionist view of knowledge considers that all individuals are constantly interacting with other individuals in an organization, whether this organization is regarded as an individual practice, primary business organization or the whole of the industry. This concept is important and underestimated by managers in the sample since it is through this social process that new knowledge is created and, existing knowledge is applied to the unique situations that are faced by both individuals and the organizations of which they are an integral part (Akgun, et.al, 2003).

The researcher addressed the managers in the sample and cited various objectives for KM efforts. The results were disappointing; however it was consistent with the gloomy understanding of knowledge by those managers (see Appendix 1). These objectives are written in order of importance according to the researcher's point of view. Table (1) shows the results.

Table 1: Survey Results

\begin{tabular}{|c|c|}
\hline $\begin{array}{c}\text { Knowledge Management } \\
\text { Objectives }\end{array}$ & Percentage \% \\
\hline 1 & 10 \\
\hline 2 & 40 \\
\hline $3,4,5,6$ & 30 \\
\hline 7,8 & 10 \\
\hline 9,10 & 10 \\
\hline 11 (Others) & - \\
\hline
\end{tabular}

From the above table, managers' perceptions towards $\mathrm{KM}$ are not encouraging. No one of those managers in the sample mentions that $\mathrm{KM}$ main objectives is to enhance internal collaboration among employees, whereas, the effective $\mathrm{KM}$ sharing is fostering innovation by encouraging the free inflow of ideas and improving the decision making process. Only $(10 \%)$ of the respondents mention that part of $\mathrm{KM}$ objectives is to capture and share best practice. The researcher believes that the first two objectives listed in the Appendix should get the high percentage and preferences or perceptions among managers. The basis for such belief is that KM programme enhance employees retention rates by recognizing the value of the employees' knowledge, and reducing costs by eliminating redundant or unnecessary processes. 
A creative approach to $\mathrm{KM}$ can be resulted in an improved efficiency, higher productivity and increased revenues practically by business function.

Thirty percent of the respondents mentioned that enhancing web site and transactional business process is the objectives of the KM efforts. The researcher found that those managers are Business Administration graduates and Head of Marketing Depts. and, therefore they express their perceptions from business point of view. However this objective importance is less than other objectives for KM such as enhancing internal collaboration or capturing and sharing best practices. Ten percent mentioned that KM objectives are enhancing supply chain management. Mangers who express this attitude are Marketing and Business Law certificates holders. Another (10\%) mentioned many different objectives such as improving customer services, streamlining response time, and getting the products and services to market faster. The researcher believes that firms' activities related to these $\mathrm{KM}$ objectives mentioned in Appendix(1), which addressed the managers in the sample, represent the consistency between organization tasks and management tasks which include: optimizing intellectual capital by producing $\mathrm{KM}$ solutions such as codification strategies and knowledge bases, knowledge sharing through the organization internal communication network facilitate a firm corporate knowledge culture, improving leaders' knowledge and, improving efficiency gains in terms of return of investment. Due to the gloomy environment concerning $\mathrm{KM}$ objectives, the researcher did not ask if these organizations measured the impact of KM on their performance, for example in terms of time reduction or gaining revenues. However it is not the intent of the paper to measure the impact of the organization performance.

\section{CONCLUSIONS}

In this paper the researcher highlights the managers' perception of KM and the importance of integration within the organizations to maintain possible competitive advantage in the UAE. In its recent introduction to business industries, firms derived many benefits from applying $\mathrm{KM}$ practices in their operations. Managers in the UAE have to practice a structured approach to manage knowledge so that can be immense benefits to every one concerned; their firms, their customers, their workers, and their organizations. The environmental forces compel firms to take $\mathrm{KM}$ initiatives. Such initiatives include imaginative leadership, investment in the essential information technology infrastructure, development of an organizational structure that allows development of trust across employees, and achievement of success. If those managers realize the potential of $\mathrm{KM}$, then they will have to meet the challenge. Management should not underestimate the unique characteristic of knowledge which is being one of the few assets that grows almost exponentially when shared. Managers should also be aware that knowledge in a meaningful manner requires a well balanced merge of technology with the organizations' culture, in away that creates an environment supporting collaboration between employees and departments.

Knowledge Management is an organizational as well as a social process, and not only a data management process. One approach to facilitating knowledge creation is through management encouragement of knowledge dispersion in their organization through communication improvements.

The focus of $\mathrm{KM}$ is to connecting employees, processes and technology for the sake of flourishing corporate knowledge. Managers should play a crucial role in making such connection possible. As there are immense potential of KM's contribution to advancement, managers should identify the critical success factors required for it. This approach include imaginative leadership and management, development of the firms' organizational structure, trust between management and employees, and investment in the suitable information technology infrastructure. These factors are important, since without the necessary underpinning conditions, there is little likelihood for KM's concept to flourish.

The researcher found that sharing and distributing knowledge among employees to improve their capabilities is one of the main reasons for $\mathrm{KM}$ integration in the organization through people and technology. The study highlights that $\mathrm{KM}$ integration is very important for managers to maintain their competitive edge and neglected by firms in the study. With a conceptual development, this paper explains the positive role of $\mathrm{KM}$ managers on knowledge creation in the organization and enhancement of trust between organization and its employees.

Limitation of the Study: As all research has limitations, first this study only views firms as information processing system, which treats a particular aspect of the organization in this paper. Second, due to the complex concept of knowledge there are different aspect of knowledge and its application, thus further study is needed. 


\section{REFERENCES}

Ali, H., and Ahmad, N.,(2006), Knowledge Management in Malaysian Banks, A New Paradigm, Journal of Knowledge Management Practices, Vol.7, No.3, pp.113.

Akgun, E., Lynn, S., and Byrne, C., (2003), Organizational Learning: A Socio-cognitive Framework, Human Relations, Vol. 56, pp. 839-868.

Alavi, M., and Leidner, E.,(2001), Knowledge Management and Knowledge Management Systems, Conceptual Foundations and Research Issues, MIS Quarterly, Vol.25, No. 1, pp. 107-136.

Bechky, A., (2003), Sharing Meaning Across Occupational Communities: The Transformation of Understanding on a Production Floor, Organization Science, A Journal of the Institute of Management Sciences, Vol.14, pp. 312-330.

Chang, K., Lee, S., and Won, I,(2005), Measuring Knowledge Management Performance, Information Management, Vol.42, No. 3, pp.469-482.

King, W., and Marks, P., (2008), Motivating Knowledge Sharing Through a Knowledge Management System, The International Journal of Management Science, Vol.36, pp. 131-146.

King, W., (2007), Knowledge Management: A Systems Perspective, International Journal of Business Systems and Research, Vol. 1, No.1 p10.

King,W.,(2006), The Critical Role of Information Processing in Creating An Effective Knowledge Organization, Journal of Database Management, vol.17, No.1, pp0115.

King, W., and Lekse, W., (2006), Deriving Managerial Benefit Form Knowledge Search: A Paradigm Shift? Information and Management, Vol.43, No. 7, pp.874883.

Keulartz, J., and Schermer, M.,(2004), Ethics in Technological Culture: A Programmatic Proposal for A Pragmatist Approach, Science Technology Human values, Vol.29, No. 1, pp.3-29.

Kanuka, D, and Garrison, D., (2007), Knowledge Management and E-learning, Available at http://Commons.ucalgary.ca.

Kuo, Y., and Chu, T.,(2004), An Investigation of Effortaccuracy Trade-off and The Impact of Self-efficacy on Web Searching Behavior, Decision Support System, Vol. 37, No. 3, pp. 331.

Kim, Y., and Street, N., (2004), An Intelligent recommendation System for Customer Targeting: Data
Mining Approach, Decision Support System, Vol. 37, pp.215-228.

Kankanhalli, A., Tanudidjaja, F., Sutanto, J., and Tan, Y., (2003), the Role of IT in Successful Knowledge Management Initiatives, Communications of the ACM, Vol.46, No.9, pp.69-74.

Lamb, R., and Kling, R.,(2003), Reconceptualizing Users as Social Actors in Information Systems Research, MIS Quarterly, Vol.27, No.2, pp.197-235.

Menon, T., and Pfeffer, J., (2003), Valuing Internal vs. External Knowledge Explaining the Preference for Outsiders, Management Science, Vol.49, No. 4, p 497.

Nissen, E., (2002), An Extended Model of Knowledge-flow Dynamic, Communications of the Association for Information Systems, Vol. 8, pp.251-266.

Nahapiet, J., and Ghoshal, S.,(1998), Social Capital, Intellectual Capital, and the Organizational Advantage, Academy of Management Review, Vol.23, No. 2, pp. 242-266.

Oliver, S., and Kandadi, R., (2006), How to Develop Knowledge Culture in Organization? A Multiple Case Study of Large Distributed Organizations, Journal of Knowledge Management, Vol. 10, No.4, pp. 6-24.

Papoutsakis, H,(2006), Linking Knowledge Management and Information technology to Business Performance: A Literature Review and A Proposed Model, Journal of Knowledge Management Practices, Vol. 7, No.1, pp. 114.

Rus, I., and Lindvall, M., (2002), Knowledge Management in Software Engineering, IEEE Software, Vol. 19, No.3, pp. 26-38.

Saint-Onge, H,(1998), How Knowledge Management Adds Critical Value To Distribution Channel Management, Journal of Systematic Knowledge Management, Vol. 1, No.1, p6.

Thiessen, V., and Looker, E., (2007), Digital Divides and Capital Conversion: The Optimal Use of Information and Communication Technology for Youth Reading Achievement, Information Communication and Society, Vol. 10, No. 2, pp.159-180.

Van, H., (2005), Running in Packs To Develop Knowledge -intensive Technologies, MIS Quarterly, Vol. 29, No. 2, pp. 365-378.

Wathen, N., and Burkell, J.,(2002), Believe It or Not: Factors Influencing Credibility on The Web, Journal of The American Society for Information Science and Technology, Vol.53, No. 2, p 134. 